\title{
The contribution of Michael Rutter ${ }^{\dagger}$
}

\author{
I. KOLVIN
}

\begin{abstract}
"Without creative personalities able to think and judge independently, the upward development of society is as unthinkable as the development of individual personality without the nourishing soil of the community".
\end{abstract}

Albert Einstein: Ideas and Opinions

By common assent Michael Rutter is the most illustrious behavioural scientist to emerge from the field of child mental health over the past 50 years. Both intellectually and in his achievements, he stands head and shoulders above his peers on the international scene.

\section{HISTORICAL}

Michael Rutter was born in the Lebanon in 1933. He received his medical education at the University of Birmingham Medical School, qualifying in 1955. At medical school an unidentified influence appeared to be operative, as 14 of his contemporaries became psychiatrists - some very distinguished. In his postgraduate period he was profoundly stimulated by three very different scientists: Grey Walter, Willy MayerGross and Aubrey Lewis, all of whom were adept at some form of intellectual games.

In 1966, Michael Rutter was appointed Honorary Consultant Psychiatrist at the Bethlem and Maudsley Hospitals, and in 1973 as the first Professor of Child Psychiatry in the UK and Commonwealth. In 1984 he was appointed Honorary Director of the Medical Research Council Unit in Child Psychiatry and, in 1994, Honorary Director of the Social, Genetic and Developmental Psychiatry Research Centre at the Maudsley Hospital and Institute of Psychiatry.

\footnotetext{
'See review article and interview pp. 480-499, this issue.
}

\section{HONOURS}

Michael Rutter has been awarded many honours, with eight honorary doctorates and honorary fellowships of three academies in the USA. He was knighted in 1992. As befits someone with his distinction, Michael Rutter has received many other academic awards, such as election as Honorary Fellow of the Royal Society of Medicine, and distinguished scientific contribution awards, of the American Psychological Association; he has also received numerous honorary fellowships of many other associations, together with many endowed lectureships and professorships.

About 20 years ago, over dinner with some senior academics, a discussion arose concerning the intellectual calibre of the then current cohort of academic psychiatrists in the UK. One view was that none merited the highest accolade of a fellowship of the Royal Society; this was challenged, with the assertion that there were four who were sufficiently meritorious. Nevertheless, subsequently, only two of these were elected to fellowships, namely $\mathrm{Mi}$ chael Rutter and Martin Roth.

Sufficient is known about Michael Rutter's contribution to support the notion that he is a creative scientist and to seek some clues about the origins and nature of his creativity. The conversation reported elsewhere in this issue (pp. 494-499), together with access to his curriculum vitae, has provided an opportunity of reviewing his life and scientific work against the backdrop of current knowledge of the psychology of creativity.

\section{PSYCHOLOGY OF CREATIVITY - A BRIEF REVIEW}

\section{Definition of creativity}

In his brief review of creativity in the Encyclopaedia of Psychology, Krippner
(1994) points out that, despite the expansive literature on the subject of creativity, the term still lacks precise definition in psychology, although there were early definitions. Mussen et al (1979) (admittedly, with children in mind) pointed out that possession by an individual of a rich reservoir of knowledge from which hypotheses can be selected should be distinguished from the freedom to use that knowledge; in brief, someone with "a rich and varied storehouse of schematic images and concepts" can be regarded as intelligent; in contrast, someone who uses these qualities in "both an original and a constructive way" can be thought of as creative. Whereas some definitions conceptualise creativity as a unique achievement and ability, others require the creative product to be of social value. Krippner concludes that, from a Western psychological perspective, creativity describes a process of bringing something new into being (May, 1975) by becoming sensitive to gaps in human knowledge; by identifying these deficiencies and searching for their solutions; by hypotheses and communicating the final product. Nevertheless, it is admitted that the creative process is not fully understood and perhaps a precise definition is unattainable (Abra, 1989). Similarly, attempts to measure creativity have encountered controversy. So-called creativity measures, which often have emphasised divergent thinking, do not necessarily correlate well with creative achievement (Gardner, 1988).

\section{Creativity and intelligence}

In an exposition of his ideas about early giftedness and later achieverments, Gardner (1993a) offers a new theoretical approach that proposes the existence of multiple intelligences. He and his colleagues (Gardner, 1983, 1993b; Ramos-Ford \& Gardner, 1991) have pointed out that the classic view of intelligence and creativity is that individuals are born with intellectual potential assumed to be quite general. Gardner takes issue with this view, arguing for the existence of seven different intellectual competences - namely, linguistic, logicalmathematical, spatial, musical, bodilykinaesthetic, interpersonal and intrapersonal. Gardner posits that each of these have genetic origins but are influenced by the resources and opportunities of the surrounding culture. He then goes on to 
make the following distinctions between giftedness and creativity (Gardner, 1993a).

A gifted individual is one who "develops intelligence in a domain more rapidly than is usual"; if the young person's achievements occur at an adult level, then he or she is considered prodigious; if the individual's contribution challenges successfully the currently commonly known area of knowledge in a particular domain, he or she is seen as creative. Gardner (1993a) lists among others two defining aspects - first, the capacity and desire to be innovative; second, the acceptance of the innovation by the cognoscente. However, Csikszentmihalyi \& Csikszenthmihalyi (1993) contend that even individuals of the highest intellect but without the right motivation and greatest degree of persistence, are unlikely to make a creative contribution. Edison, too, perceived invention as " $1 \%$ inspiration and $99 \%$ perspiration" (Abra, 1989).

It has been asserted that 'rote memory' may be unhelpful and even damaging, as it may be associated with a tendency to retain past, familiar images, whereas creativity seeks the new (Abra, 1989). However, Abra states that other aspects of memory seem critical; indeed, imagination can be viewed as itself an "activity of memory striving for symbolic expression" of the already known.

\section{Characteristics of the creative personality}

Krippner (1994) emphasises that characteristics of the creative personality are high energy, broad interests, attraction to complexity, independence of judgement, a sense of autonomy, good intuition, self-confidence and, finally, perception of oneself as a creative person. A further concept is motivation to achieve, which McClelland (1953) termed n Ach. Such a characteristic is marked by competition either with an external standard of excellence or with the subject's own internal aspirations. The notion is not without controversy.

Various other features are reported in the literature and some merit brief comment. Creative individuals are often perfectionists, setting high and unattainable goals for themselves. Allied to this is self-confidence, with creative individuals generally being more self-assertive, dominant and independent (Abra, 1989). These qualities allow creators to take chances and face antipathy and risks, and even invite periodic failure. A streak of self-absorption is often reported, probably because creativity demands time, energy and drive, as creators need to put their work before all else, often including social obligations and personal relationships. Insufficient self-absorption is said to have compromised more than one talent (Abra, 1989).

Persistence and perseverance are two noteworthy qualities. However, when some creators were asked about the ingredients of their success like Edison, they tended to place imagination as an adjunct to such qualities as perseverance, dedication and stamina (Rossman, 1931; Abra, 1989). For Gruber (1980), a hallmark of genuine creativity is a lifetime of continuous effort. Often creators resist authority, resent regimentation, and are less critical of themselves. However, some creators tend to be riddled with doubts about their work perhaps because of a concern that their talents may suddenly wither.

Some consider flexible thinking as virtually mandatory, as it increases the likelihood of achieving novel combinations of different concepts or constructs (Abra, 1989). Tolerance of ambiguity is thought to be a core quality (Barron, 1963). Whereas some writers emphasise problem-solving and the ability of find answers to pertinent and impertinent questions, others consider that the essence of the creator's ability is problem-finding.

Gardner (1993a) concludes that there are a predictable set of personality traits that are motivated chiefly by intrinsic factors. However, Csikszentmihalyi \& Csikszentmihalyi (1993) highlight three fundamental characteristics identified by other writers - namely, persistence or driving absorption, the ability to continue to work in the face of failure and adversity, and a great curiosity that leads to the recognition of new challenges (Simonton, 1988).

An often-posed question is where the creative individual finds his or her reward and this theme is addressed by Csikszentmihalyi \& Csikszentmihalyi (1993)-some creators have reported their endeavours as so much fun (Chandrasekhar, 1987), or obtain a deep sense of enjoyment when working in their field (Schlick, 1934). Hence, mostly the rewards are intrinsic, with less dependence on external recognition (Csikszentmihalyi \& Csikszentmihalyi, 1993).

\section{Changes in creativity with age}

Most reviews suggest that there are changes with age that adversely affect creative productivity (Abra, 1989). Commonly, the originality peak is predominant early and more pronounced in the sciences, such as mathematics, but also poetry, in contrast to the other arts and humanities. Subsequently, the amount of creative work falls off. However, is this a decline? There is evidence that quantity declines less rapidly than quality. Abra (1989) argues that creativity may simply change rather than decline with age, with different stylistic and thematic concerns gaining priority, but that scientists need flexibility in order that they may continually adopt new perspectives. Nevertheless, such sweeping generalisations obscure the fact that there are many exceptions, of immensely creative individuals who continue successfully into their twilight years (Abra, 1989). Further, in some fields the greatest creators maintain enormous productivity at an immense pace across the life span (Albert, 1983).

The above review assumes that creativity concerns only life-long continuous achievement, but there is also the important matter of the creative individual's supreme endeavour (Abra, 1989). Others assert that creative individuals usually pursue a network of interrelated enterprises over the course of their productive lives, with creative insights emerging gradually and the creative impulse taking shape over the life span through interaction in human environments (Gardner, 1993a). The theme of peaks of endeavour is covered in the penultimate section.

\section{Case studies of creativity}

One way of understanding creativity is the single or multiple case-study approach. Gardner $(1983,1993 a)$ used a variant of this approach to study the range of multiple intelligences, previously proposed, as representative of the seven forms of intellectual competence described in the section on 'creativity and intelligence'. He chose seven creative individuals as representative of each of the above forms of intelligence. This is enormously important work that underlines the creative potential of idiographic approaches which enrich the nomothetic approach in this field of endeavour.

Gardner (1993a) reports that, although these seven individuals differed according to type of intelligence they represented, they were "strikingly similar in personality" - hard-driving, extremely ambitious and sacrificing all for their work. Their initial breakthrough took 10 years with 
subsequent breakthrough about 10 years later. At the time of breakthrough, these individuals needed both cognitive and affective support. There were other crucial findings, one of which is relevant to this review. Although all creators engaged in problem-solving, this was complemented by four other factors - the creation of a broad encompassing theory; the creation of a permanent work genre; a performance that is ritualised; and the creation of a performance that has a 'high stake'.

Importantly, most of those selected for study did not grow up under conditions of adversity; and further, were encouraged in their sense of curiosity by their environments. Their families had high moral standards with an expectation of achieving high standards in their work. Against this background, they sought out a coterie of others who were similarly motivated; all were drawn to major cities of Europe.

Csikszentmihalyi \& Csikszentmihalyi (1993) contend that, the relationship between early family environment and later creative achievement is inconclusive, with some creative individuals having been exposed to early life tragedy and trauma. They suggest that, in those individuals experiencing early life adversity or atypical experiences, there may, as a consequence, be a sense of marginality that may give rise to unconventional thinking and originality. They emphasise, particularly, parental loss. Such explanations are tantamount to 'steeling effects' in the face of adversity, but these are relatively uncommon phenomena. Other workers, such as Gardner (1993a), offer a different view, emphasising the importance of good parental standards and expectations, parental support and warmth that may give rise to "self-confidence, inner harmony, endurance and the development of skills" (Csikszentmihalyi \& Csikszentmihalyi, 1993). Others suggest that both influences may be true, with creativity being related by a U-shaped function to early life experiences.

\section{NATURE AND ORIGINS OF MICHAEL RUTTER'S CREATIVITY}

Turning to Michael Rutter, it is not possible to offer relevant comment on all the themes covered in the above brief review of the psychology of creativity. However, it is possible to provide some pointers. So far, the scholarly output by Michael Rutter over his effective academic life span of about 35 years has been prodigious with 35 books and over 400 publications; which, on average, amounts to one book and 12 publications a year. The quantity is underpinned by innovation and paralleled by quality.

Another way of reviewing his creativity is by examining the 'breakthroughs'. These came frequently and can be listed by decade starting at the time of his appointment as a consultant at Maudsley Hospital.

(a) In the first decade (1965-1974) the themes were autism, classification, epidemiological studies (Isle of Wight) and children of sick parents.

(b) The second (1975-1984) was underpinned by epidemiological studies: included were (i) comparative studies of attainment and adjustment in two geographical areas; (ii) schools as institutions (represented in his book Fifteen Thousand Hours, Rutter et al, 1979); (iii) developmental psychiatry including such themes as cognitive and psychiatric sequelae of head injury; and finally (iv) the subject of deprivation, as represented by his landmark book on Maternal Deprivation Reassessed and by his studies on women institutionalised in childhood.

(c) In the third (1985-1994) there was a focus on resilience in the face of adversity, genetic influences generally and adult outcomes of childhood disorders.

(d) In the fourth (1995-present) there have, so far, been breakthroughs on the genetics of autism and also on turning points in adult life following psychosocial adversity in childhood and on the sequelae of profound early privation.

\section{Creativity and intelligence}

Michael Rutter has very high intelligence in diverse domains. He has a good capacity for so called convergent, divergent and lateral thinking; this is complemented by a high capacity for abstract thought, with an ability to make both logical and irrational connections and in thought, to 'try out' competing solutions. He has strong imaginative powers and has a capacity to focus these without restricting their scope; and also an ability to use intuitive thinking. $\mathrm{He}$ cannot be pigeon-holed into one of Gardner's, 'intellectual competence categories'. Rather, it can be argued that his skills straddle at least linguistic and logical-mathematical competences.
His staggering productivity has a basis in the interlocking of his formidable intellectual powers and his capacity for both high-level conceptualisation and skills in logical analysis of scientific problems. One of his greatest skills is to explore perceptively the landscape of child development, to identify deficiencies in knowledge and select those which indicate realistic problems for science, to think clearly and logically about them, to tease out the various aspects, and to set up potentially fruitful hypotheses and test these with rigorous modern methods. Innovation is the keynote, both within themes under study and in new areas of research. He claims not to have a good rote memory, and this is probably true; however, those observing his performance in workshops or seminars will attest to a prodigious knowledge with a capacity for using this in a constructive and innovative way.

\section{Personality characteristics}

Attraction to intellectual and scientific challenge appears to be a core ingredient of his personality and, together with his insatiable curiosity, appears to be the underpinning of his becoming a questioning scientist who explores complex issues. Many reviewers describe creators, as willing to live with ambiguity, when necessary. What Rutter describes is intellectual flexibility in conjunction with a willingness to change his ideas, together with a preference for making definite statements that are open to disproof. However, he never has shown a respect for received wisdom that may deter a new correct explanation but, rather, has displayed a healthy scepticism, with a readiness to doubt traditional beliefs and/or evidence. He combines this with a capacity for tolerating ignorance, doubt and ambiguity. Furthermore, he has the courage of never allowing a fear of making a mistake to inhibit him from exploring good ideas, in presenting his opinions and in taking risks with hypotheses. Persistence and perseverance are represented in his single-minded dedication. These qualities are blended with his high drive, energy and high-achievement motivation (n Ach). A necessary, seldom-described quality, is his acceptance of monotony, when necessary, which is not an uncommon phenomenon in any research endeavour. To sum up, many of the components of successful research call for inspirational or creative imagination and much of the rest requires 
meticulous, disciplined slogging, throughout the testing processes-all qualities possessed by Michael Rutter.

The awareness of the uniqueness of his self and his capacity for independent thinking never deterred him from working collaboratively across disciplines or within multi-disciplinary teams. The above qualities and characteristics add up to something very powerful with an undoubted creative component. However, the creativity is harnessed and disciplined and that is an essential accompaniment.

\section{Environmental influences}

Environmental influences cannot be ignored. The childhood family life of Michael Rutter was characterised by ongoing good relationships, but also family mobility. His awareness of the importance of individual differences and cultural variations emerge again and again as themes in his research, which he attributes to these background experiences. However, this was tempered by other experiences. It was not long after the Second World War when Michael Rutter and his contemporaries entered medical school-and most, as children, had been evacuated during the war. Perhaps it is not surprising that some of them, including Michael Rutter, became interested in the influence of environment on functioning and a form of Zeitgeist that led him and so many of his contemporaries into psychiatry.

Equally important is his attribution of early experiences to the fostering of independent thinking and a sense of autonomy, as well as a willingness to question socalled known facts. During his school years he was allowed, when relevant, to challenge and resist convention and also was allowed to indulge in intellectual curiosity, which, like that of the Elephant's child in Kipling's story, was the forerunner of a life-long "satiable curiosity". Like many creators, his reading in the school years was continuous and varied and apparently not always endorsed by his teachers. Thus, he entered postgraduate academia with an ability to link, conceptually, facts and ideas. $\mathrm{He}$ is generous in ascribing much of his expansion of such abilities to his mentors: the particular qualities that he mentions are their interests in observing unusual phenomena, skills in clinical observation, ways of generating hypotheses and, all in all, the logic of the science of medicine.
When mistaken about an issue, there is a willingness to undertake a ruthless examination and self-critical attitude of the reasons for this-such approaches prove to be supportive rather than threatening of his self-confidence.

These skills with intellectual and scientific concepts crystallised during his contact with Aubrey Lewis and Neil Kessel and set him on the path to becoming a thinking scientist who enjoyed engaging in scientific challenges - perhaps even more than finding solutions. Although he admits that his early interests reflected the scientific approaches and ways of thinking employed by his mentors, he adds these were shaped by his own temperament. Lewis also arranged for him to go to the USA to learn about research in child psychiatry and psychology from Stella Chess, Alex Thomas and Herb Birch.

\section{Changes in creativity with age}

There is a substantial literature on the longitudinal connection between personal age and outstanding achievements (Simonton, 1988). One main issue is whether there is an optimum age for an individual to make a substantial contribution. Lehman (1962) described a tendency for achievement to be a curvilinear single-peak function of age (Simonton, 1987). The different fields of endeavour are associated with a range of peaks, such as an early peak, perhaps in the late 20 s or early $30 \mathrm{~s}$, followed by a rather steep decline; as previously mentioned, such a pattern is true of poetry and pure mathematics. At the other extreme there is a more leisurely rise to a comparatively late peak in the late $40 \mathrm{~s}$ or even $50 \mathrm{~s}$, often with a minimal drop-off afterwards, and this apparently occurs in novel-writing, history and medicine (Lehman, 1953; Simonton, 1975). Simonton argues that these crossdiscipline contrasts do not appear to be arbitrary but, rather, are shown to be stable across different cultures. He also argues that the determinants of productivity with age may have a basis in intrinsic informationprocessing requirements rather than extrinsic influences. Other workers have described bimodal separate peaks, with a secondary upswing near retirement age; however, this resurgence is not always apparent, and Simonton states that when present it is, without exception, far smaller than the regular maximum output observed in the middle of the subject's career. Another pattern is a bimodal productivity distribution, with two age-peaks of approximately equal magnitude (Abt, 1983).

The above patterns have been described in greater detail as they are relevant to Michael Rutter's performance over the years. An examination of his real life achievement provides a view of his achievement peaks. A review of his books, chapters and scientific papers, reveals a steady buildup of achievement until his mid-40s, but thereafter there is no steady climb - rather a number of valleys and peaks right up to his mid-60s, when there is, again, a resurgence that is certainly not less than the maximum observed in the middle of his career. If one confines the achievements to scientific papers, there is a late career surge in his early $60 \mathrm{~s}$. Throughout his career there has been an association between quantity and quality of output. The analysis of his creative breakthroughs indicates that there have never really been fallow periods. It is remarkable that he has continued to develop as a scientist and a creator well into his $60 \mathrm{~s}$. Perhaps his enjoyment of academic debate, which forces him to search for and offer solutions and to confront challenges to his ideas, has facilitated his continuing intellectual growth.

\section{SOME FINAL COMMENTS}

Michael Rutter combines many of the qualities and ingredients reported as shaping a creative individual - in part, early family stimulation; in part, intellectual nourishment in the school and post-school years; and in part, intellectual and scientific stimulation as a postgraduate student in conjunction with his intrinsic insatiable curiosity and his attraction to challenge. These extrinsic factors appear to be clearcut; however, there are other qualities that are specific to him, already described - it is possible only to speculate about their relative contribution to his achievements. There will be continuing debate about the contribution of diverse mentors, about the culture within his family and, of course, the importance of that breeding ground for UK psychiatric academia, the Maudsley Hospital and the Institute of Psychiatry.

$\mathrm{He}$ is a 'one-off' in his own field, with no other behavioural scientist - previously or currently - applying sophisticated scientific skills, gaining such respect from his scientific peers and enjoying such a wide lay and specialist readership during his lifetime. 
However, one highly creative personality did emerge in an allied field. This was John Bowlby, who can be viewed as falling into Gardner's intrapersonal intellectual competence category. He was not a research scientist in the same sense as $\mathrm{Mi}$ chael Rutter. His approach was different, being more idiographic, inductive and theoretical than scientific. His theory of attachment proved a supreme breakthrough and has been the inspirational source of an expanding worldwide research industry.

Michael Rutter's work has many strands and phases and, in the field of psychiatry, his eminence transcends the usual disciplinary barriers - from child to adult and also to forensic psychiatry and, even further, into the biological, social and psychological sciences. The strands of design, method and analyses are notable: each earlier strand of his research has appeared to move into an expanding scientific web, with that web constituting an important resource for future research. The web is not static, as it appears to grow in its associations and is receptive to inclusion of new strands. Frequently this web has allowed him, while working on a current hypothesis, to use the results of that to fashion other hypotheses.

Some consider the most creative contribution of Michael Rutter, was to recognise that child mental health was capable of being subjected to the self-same empirical research design and method used in other branches of medicine. He then proceeded, collaboratively with other scientists from allied disciplines, to apply these methods to child and family mental health research. In this he spearheaded the dramatic transformation of the subject.

Finally, a matter of concern: Michael Rutter was the architect of his own academic destiny which included the seek- ing of relevant training and the development of new skills in response to the needs of each particular research task with which he is involved. Hence, the question arises whether modern-day trends, with often rather prescriptive formal training programmes, will hinder the emergence of future creators in this field?

\section{ACKNOWLEDGEMENTS}

I thank Dora Black, Robert Cawley, Lionel Hersov and Anne Le Couteur for their valuable comments and constructive criticisms about an earlier draft of this paper, and Heather Russell for diligent reading of and comments on the manuscript. This paper was written while the recipient of a Leverhulme Emeritus Fellowship.

\section{REFERENCES}

Abra, J. (1989) Changes in creativity with age: data, explanations, and further predictions. International journal of Ageing and Human Development, 28, 105-126.

Albert, R. S. (1983) Toward a Behavioral Definition of Genius. In Genius and Eminence (ed. R. S. Albert), pp. 57-72. New York: Pergamon Press.

Abt, H. A. (1983) At what ages do outstanding American astronomers publish their most cited papers? Publication of the Astronomical Society of the Pacific. 95. 113-116.

Barron, F. (1963) The needs for order and for disorder as motives in creative activity. In Scientific Creatinty: Its Recognition and Development. (eds, C.W. Taylor \& F. Barron). pp. 153-160. New York: John Wiley and Sons.

Chandrasekchar, S. (1987) Iruth and Beauty. Chicago, IL: University of Chicago Press.

Csilkszentmihabyi, M. \& Czikszentmihalyi, I. S. (1993) Family influences on the development of giftedness. In The Origins and Development of High Ability (Ciba Foundation Symposium 178) (eds G. R. Bock \& K. Ackrill). pp. 187-206. Chichester: Wiley

Gardner, H. (1983) Frames of Mind: The Theory of Multiple Intelligences. New York: Basic Books.

- (1988) Creativity: an interdisciplinary perspective. Creativity Research journal, I, 8-26.
_ (19930) The relation between early giftedness and later achievement. In The Origins and Development of High Ability (Ciba Foundation Symposium 178) (eds G. R. Bock \& K. Ackrill), pp. 175- 186. Chichester: Wiley

- (1993b) The Creotors of the Modern Era. New York: Basic Books.

Gruber, H. (1980) The evolving systems approach to creativity. In Toward a Theory of Psychological Development. (eds S. Modgill \& C. Modgill). pp. 269-299. Atlantic Highlands, NJ: Humanities Press.

Krippner, S. (1994) Creativity, In Encyclopaedia of Psychology (ed. R. J. Corsini). pp. 341-342. Chichester: Wiley.

Lehman, H. C. (1953) Age and Achievement. Princeton, NJ: Princeton University Press.

- (1962) More about age and achievement. Gerontologist, 2, 141-148.

McClelland, D., Atkinson, J., Clark, R., et al (1953) The Achievement Motive. New York: Appleton-CenturyCrofts.

May, R. (1975) The Couroge to Create. New York: W.W. Norton \& Co

Mussen, P. H., Conger, J. J. \& Kagan, J. (1979) Child Development and Personality (5th edn). pp. 262-264. New York: Harper \& Row.

Ramos-Ford, V. Eardner, H. (1991) Giftedness from a multiple intelligences perspective. In Handbook of Gifted Education (eds N. Colangelo \& G. A. Davis), pp. 55-64. Needham Heights, MA: Allyn \& Bacon.

Roseman, J. (1931) The Psychology of the Inventory Washington, DC: Inventors Publishing.

Rutter, M. (1981) Maternal Deprivotion Reassessed (2nd edn). Harmondsworth: Penguin.

_., Maughan, B., Mortimore, P., et al (1979) Fifteen Thousand Hours: Secondary Schools and Their Effects on Children. Cambridge, MA: Open Books.

Schlick, M. (1934) Uber das Fundament der Erkentniss, Erkentniss 4 (English translation in Logical Positivism. ed. A. J. Ayer). New York: Free Press.

Simonton, D. K. (1975) Age and literary creativity: a cross-cultural and transhistorical survey. journal of Cross-Cultural Psychology, 6. 259-277.

- (1987) Developmental antecedents of achieved eminence. Annals of Child Development, 5. 131-169.

- (1988) Age and outstanding achievement: what do we know after a century of research? Psychological Bulletin, 104, 251-267. 